\title{
Salinização do solo e desenvolvimento de meloeiro com a aplicação de resíduo de caranguejo
}

\author{
Francisco J. Ferreira ${ }^{1}$, Aiala V. Amorim ${ }^{2}$, Francisco J. F. de Araújo ${ }^{3}$, \\ Claudivan F. Lacerda ${ }^{1} \&$ Marisete D. Aquino ${ }^{3}$
}

\begin{abstract}
RESU MO
Os resíduos de caranguejo apresentam potencial como adubo orgânico. Buscou-se neste trabalho, avaliar os efeitos da aplicação de resíduo de caranguejo U çá na salinização do solo, no crescimento e nos teores de clorofila e solutos orgânicos e inorgânicos de plantas de melão. 0 experimento foi conduzido em casa de vegetação no período de maio a junho de 2010 . Utilizaram-se oito tratamentos correspondendo às percentagens de $0,1,3,5,10,20$ e $30 \%$ de resíduo de caranguejo e um tratamento contendo adubação mineral (solução de Hoagland), todos com seis repetições. Trinta dias após 0 plantio foram avaliados em extrato solo : água (1:1) o pH, a condutividade el étrica (CE) e os teores de $\mathrm{Na}^{+}$ e $\mathrm{K}^{+}$. N as plantas foram avaliados a produção de massa seca da parte aérea, área foliar, massa seca da raiz e os teores foliares de clorofila e de solutos orgânicos e inorgânicos. 0 incremento nas concentrações de resíduos de caranguejo aumentou significativamente os valores de $\mathrm{pH}, \mathrm{CE}, \mathrm{Na}^{+}$e $\mathrm{K}^{+}$do solo. Foram observadas tendências quadráticas para as variáveis de crescimento e os teores de clorofila na planta. 0 aumento na $\mathrm{CE}$ e no teor de $\mathrm{Na}^{+}$contribuiu para reduzir o crescimento das plantas nos níveis mais elevados de resíduos de caranguejo.
\end{abstract}

Palavras-chave: adubação, U cides cordatus, Cucumis melo

\section{Effects of crab residue in soil salinization and development of melon}

\begin{abstract}
The residue of crab show potencial as organic fertilizer. This study evaluated the effect of applying concentrations of residue of crab $U$ çá in sanilization of soil, on growth, chlorophyll and organic and inorganic solutes in melon. This experiment was conducted under greenhouse conditions from $\mathrm{M}$ ay to June in 2010. Eight treatments were used corresponding to percentage of $0,1,3,5,10,20$ and $30 \% \mathrm{crab}$ residue and a treatment containing mineral fertilizers ( $\mathrm{H}$ oagland solution), each with six replications. Thirty days after sowing in the soil : water $(1: 1)$ extract: $\mathrm{pH}$, electrical conductivity (EC), and $\mathrm{K}^{+}$and $\mathrm{Na}^{+}$ were evaluated. In plants dry mass of shoot, leaf area, root dry mass and leaf contents of chlorophyll and organic and inorganic solutes were evaluated. The increase in concentrations of crab residue significantly increases the $\mathrm{pH}, \mathrm{EC} \mathrm{N} \mathrm{a}$ and $\mathrm{K}^{+}$in the soil. Q uadratic trends were observed for growth parameters and chlorophyll contents in the plants. The increase in the EC and the levels of $\mathrm{Na}^{+}$contributed to reduce plants growth in the higher levels of crab residue.
\end{abstract}

Key words: fertilization, Ucides cordatus, Cucumis melo

Trabalho submetido e selecionado no primeiro Simpósio Brasileiro de Salinidade realizado de 12-15/10/2010 em Fortaleza, Ceará, Brasil ${ }^{1}$ DEN A/U FC Av. M ister Hull s/n, Campus do Pici, CEP 60451-970 UFC, Fortaleza, CE, Fone: (85) 3366-9127. E-mail: jardelsonaur@gmail.com; cfeitosa@ufc.br

${ }^{2}$ DF/U FC E-mail: aialaamorim@hotmail.com

${ }^{3}$ DEHA/UFC E-mail: freire-araujo@hotmail.com; marisete@ufc.br 


\section{INTRODUÇÃO}

A procura por alimentos orgânicos vem aumentando no Brasil nos últimos anos, o que pode ter refletido no aumento de propriedades que trabalham com esse tipo de cultivo no país (Camargo et al., 2004). Esta prática agrícola se caracteriza por manter a produção evitando ou praticamente excluindo os fertilizantes sintéticos, sendo a adubação caracterizada pela utilização de insumos provenientes de compostos orgânicos. Segundo Rodrigues et al. (2008), quando fornecida em dose adequada, a matéria orgânica de origem animal ou vegetal exerce efeitos positivos sobre o rendimento das culturas devido, principalmente, ao complexo de nutrientes nela contidos.

Esse tipo de agricultura tem-se tornado uma alternativa viável para assegurar a aceitação do melão produzido no Brasil pelo mercado internacional, bem como aumentar seu valor de comercialização (Duenhas, 2004). Os maiores produtores brasileiros dessa olerícola se concentram na região Nordeste, a qual contribui com mais de $90 \%$ da produção nacional (Menezes et al., 2001). Para se obter altas taxas de produtividades e frutos de melão com boa qualidade, é necessário que seja utilizada uma adubação adequada.

São vários os compostos que podem funcionar como adubo orgânico, dentre eles destacam os resíduos de caranguejo Uçá (Ucides cordatus L.). O consumo desse crustáceo no município de Fortaleza é cerca de 75 t mês ${ }^{-1}$ (IBAMA, 2006), o que gera grande quantidade de lixo que pode ser reaproveitado como adubo orgânico; entretanto, a utilização desses resíduos pode alterar as propriedades físicas, químicas e biológicas do solo, desencadeando um processo de salinização e comprometendo o desenvolvimento das plantas.

Alguns trabalhos registram a importância da casca de caranguejo como excelente aditivo para reduzir a incidência de fusariose e para promover o crescimento de plantas (Benchimol et al., 2006). No entanto, os estudos relacionados com os efeitos da aplicação desses resíduos na salinização, no crescimento e em respostas bioquímicas das plantas, são escassos.

Objetivou-se, portanto, no presente trabalho, avaliar os efeitos da aplicação de diferentes percentagens de resíduos do caranguejo Uçá (Ucides cordatus L.) na salinização do solo, no crescimento e em algumas variáveis bioquímicas de plantas de melão.

\section{MATERIAL E MÉTODOS}

O experimento foi conduzido em casa de vegetação do setor de Fisiologia Vegetal, do Departamento de Bioquímica e Biologia Molecular, da Universidade Federal do Ceará (UFC), localizada no Campus do Pici, Fortaleza, Ceará, no período de maio a junho de 2010. Os valores médios de temperatura e umidade relativa do ar registradas com o auxílio de um termohigrógrafo durante o período experimental foram, respectivamente, $30,1 \pm 0,99^{\circ} \mathrm{C}$ e $68,87 \pm 1,74 \%$. As análises químicas e bioquímicas foram realizadas nos laboratórios de Fisiologia Vegetal dos Departamentos de Bioquímica e Biologia Molecular (DBBM) e Engenharia Agrícola (DENA) da UFC.
Em um vaso com capacidade para $3 \mathrm{~L}$ foram colocadas 5 sementes de melão cv. Imperial (Cucumis melo L.) para germinar, sendo que 10 dias após o plantio foi realizado um desbaste, deixando-se apenas 2 plantas por vaso. Os vasos foram preenchidos com mistura de resíduo de caranguejo e solo, na base de volume, com cada vaso recebendo um volume final de 3 L. Uma amostra do solo classificado como Argissolo Vermelho Amarelo, foi coletado na profundidade de 0 a 0,2 m, na área experimental do Departamento de Engenharia Agrícola da Universidade Federal do Ceará, apresentando as seguintes características: textura franco arenosa, densidade $1,4 \mathrm{~kg} \mathrm{dm}^{-3}$, pH6,3, $\mathrm{CE}_{1: 1} 0,2 \mathrm{dS} \mathrm{m}^{-1}$, e 1,5; 1,1; 0,11 e 0,26 $\mathrm{cmol}_{\mathrm{c}} \mathrm{dm}^{-3} \mathrm{de} \mathrm{Ca}^{2+}$, $\mathrm{Mg}^{2+}, \mathrm{K}^{+} \mathrm{e} \mathrm{Na}{ }^{+}$, respectivamente. Os tratamentos consistiram das seguintes percentagens de resíduo de caranguejo seco: 0 , $1,3,5,10,20$ e $30 \%$, com as plantas sendo irrigadas com água destilada mantendo-se o solo na capacidade de campo, em turno de rega de dois dias. Utilizou-se um tratamento adicional, sem resíduo de caranguejo, sendo as plantas irrigadas com solução de Hoagland \& Arnon (1950), no mesmo turno de rega das que foram submetidas aos tratamentos contendo resíduo de caranguejo.

O delineamento experimental utilizado foi inteiramente casualisado com oito tratamentos e seis repetições, com duas plantas por vaso. Os resíduos de caranguejo obtidos na região de Fortaleza foram secados, submetidos a moagem em um moinho de bolas e em seguida peneirados em uma malha de número 20, tendo como produto final partículas com diâmetros inferiores a $0,84 \mathrm{~mm}$. O pó obtido foi utilizado no experimento e apresentava a seguinte composição (Tabela 1).

Tabela 1. Dados da análise dos resíduos de caranguejo

\begin{tabular}{lcc}
\hline Amostras & Unidade & Caranguejo pós-mesa \\
Nitrogênio & $\left(\mathrm{g} \mathrm{kg}^{-1}\right)$ & 17,1 \\
Fósforo & $\left(\mathrm{g} \mathrm{kg}^{-1}\right)$ & 5,0 \\
Potássio & $\left(\mathrm{g} \mathrm{kg}^{-1}\right)$ & 0,8 \\
Cálcio & $\left(\mathrm{g} \mathrm{kg}^{-1}\right)$ & 267,9 \\
Magnésio & $\left(\mathrm{g} \mathrm{kg}^{-1}\right)$ & 17,6 \\
Ferro & $\left(\mathrm{mg} \mathrm{kg}^{-1}\right)$ & 310,83 \\
Cobre & $\left(\mathrm{mg} \mathrm{kg}^{-1}\right)$ & 13,66 \\
Zinco & $\left(\mathrm{mg} \mathrm{kg}^{-1}\right)$ & 44,51 \\
Manganês & $\left(\mathrm{mg} \mathrm{kg}^{-1}\right)$ & 24,39 \\
Cloretos & $\left(\mathrm{g} \mathrm{kg}^{-1}\right)$ & 0,54 \\
Sódio & $\left(\mathrm{g} \mathrm{kg}^{-1}\right)$ & 1,68 \\
Matéria Orgânica - MO & $\left(\mathrm{g} \mathrm{kg}^{-1}\right)$ & 164,9 \\
pH & $(1: 2,5)$ & 9,5 \\
Condutividade Elétrica - CE & $\left(\mathrm{dS} \mathrm{m}^{-1}\right)$ & 4,7 \\
\hline Fonte: Araújo et al. (2009) & \multicolumn{2}{l}{}
\end{tabular}

Aos 30 dias após o plantio (DAP) foram feitas as medições de clorofila com um medidor portátil (SPAD-502, Minolta, Osaka, Japan), as plantas foram coletada, e os órgãos vegetativos separados para as seguintes determinações: área foliar total com o auxílio de um medidor de superfície (LI-3000, Li-Cor, Lincoln, USA), massa seca da parte aérea (MSPA) e raiz (MSR). Para obtenção da massa seca os respectivos órgãos vegetais foram colocados em sacos de papel e postos para secar em uma estufa de circulação forçada de ar a $60^{\circ} \mathrm{C}$ até atingirem peso constante.

O material vegetal seco foi triturado e os extratos foram obtidos através da homogeneização de $100 \mathrm{mg}$ do pó vegetal 
seco, com $10 \mathrm{~mL}$ de água desionizada durante $60 \mathrm{~min}$, sob agitação constante a $45^{\circ}$ (Cataldo et al., 1975). O homogenato foi centrifugado a $3000 \mathrm{x}$ g por $15 \mathrm{~min}$, e o sobrenadante filtrado em papel de filtro e armazenado a $-25^{\circ} \mathrm{C}$.

Determinaram-se os teores de carboidratos solúveis de acordo com Dubois et al. (1956) e os de N-aminossolúveis segundo Yemm \& Cocking (1955). No mesmo extrato em que foram determinados os solutos orgânicos determinaram-se também os teores dos íons $\mathrm{K}^{+} \mathrm{e} \mathrm{Na}^{+}$por fotometria de chama.

Após a coleta das plantas o solo foi retirado e as amostras secadas ao ar, destorroadas e peneiradas em malha de $2 \mathrm{~mm}$ de diâmetro. Obteve-se o extrato através da mistura do solo com água desionizada na proporção 1:1 (v/v), sendo o pH e a CE obtidos nessa suspensão. Esse extrato foi filtrado utilizandose filtros de papel e em seguida foram determinados os teores de $\mathrm{Na}^{+}$e $^{+}$por fotometria de chama.

Os dados foram submetidos às análises de variância, testando-se modelos de regressão entre as variáveis obtidas e as percentagens de resíduo aplicadas, através do programa computacional SAEG/UFV 9.0.

\section{RESULTADOS E DISCUSSÃO}

Os resultados de $\mathrm{pH}$ do solo não se ajustaram a nenhuma linha de tendência (Figura 1A); no entanto, observa-se um aumento no $\mathrm{pH}$ com a aplicação de resíduos de caranguejo, mesmo em baixas concentrações, o que se deve à grande quantidade de cálcio e à elevada alcalinidade do resíduo utilizado (Tabela 1).

Na Figura 1B é possível verificar que 99,57\% dos dados estão sendo explicados pela reta de regressão, ou seja, à medida em que há um incremento nas percentagens dos resíduos de caranguejo no solo, a CE aumenta, em virtude da elevada concentração de sais nesse material (Tabela 1). Os teores de $\mathrm{Na}^{+}$e $\mathrm{K}^{+}$foram maiores nas percentagens mais elevadas da aplicação dos resíduos de caranguejo (Figura 1C e 1D), coincidindo com os aumentos nos dados de CE (Figura 1B). Além disso, observa-se que os teores de $\mathrm{Na}^{+}$são superiores aos de $\mathrm{K}^{+}$em todos os tratamentos em que foram aplicados resíduos de caranguejo (Figura 1C e 1D), refletindo, em parte, a composição desse material.

A massa seca da parte aérea (MSPA), a área foliar (AF) e a massa seca da raiz (MSR), tiveram um comportamento quadrático em função das percentagens de aplicação dos resíduos de caranguejo (Figura 2). Inicialmente, nota-se tendência de aumento nessas três variáveis (Figura 2) devido, provavelmente, à maior disponibilidade de nutrientes minerais contidos nos resíduos de caranguejo (Tabela 1). A redução no crescimento das plantas com o aumento da percentagem de resíduos de caranguejo pode estar associada ao aumento da salinidade do substrato (Figura 1B) atingindo, sem dúvida, níveis que superam a salinidade limiar da cultura.

Através do cálculo da derivada da reta é possível identificar que o valor máximo de MSPA, AF e MSR pode ser obtido na percentagem de 15,08, 14,54 e 15,66\% de resíduo de caranguejo, respectivamente. A partir desses valores observa-se tendência de queda, o que pode ser explicado, pelo menos em parte, em
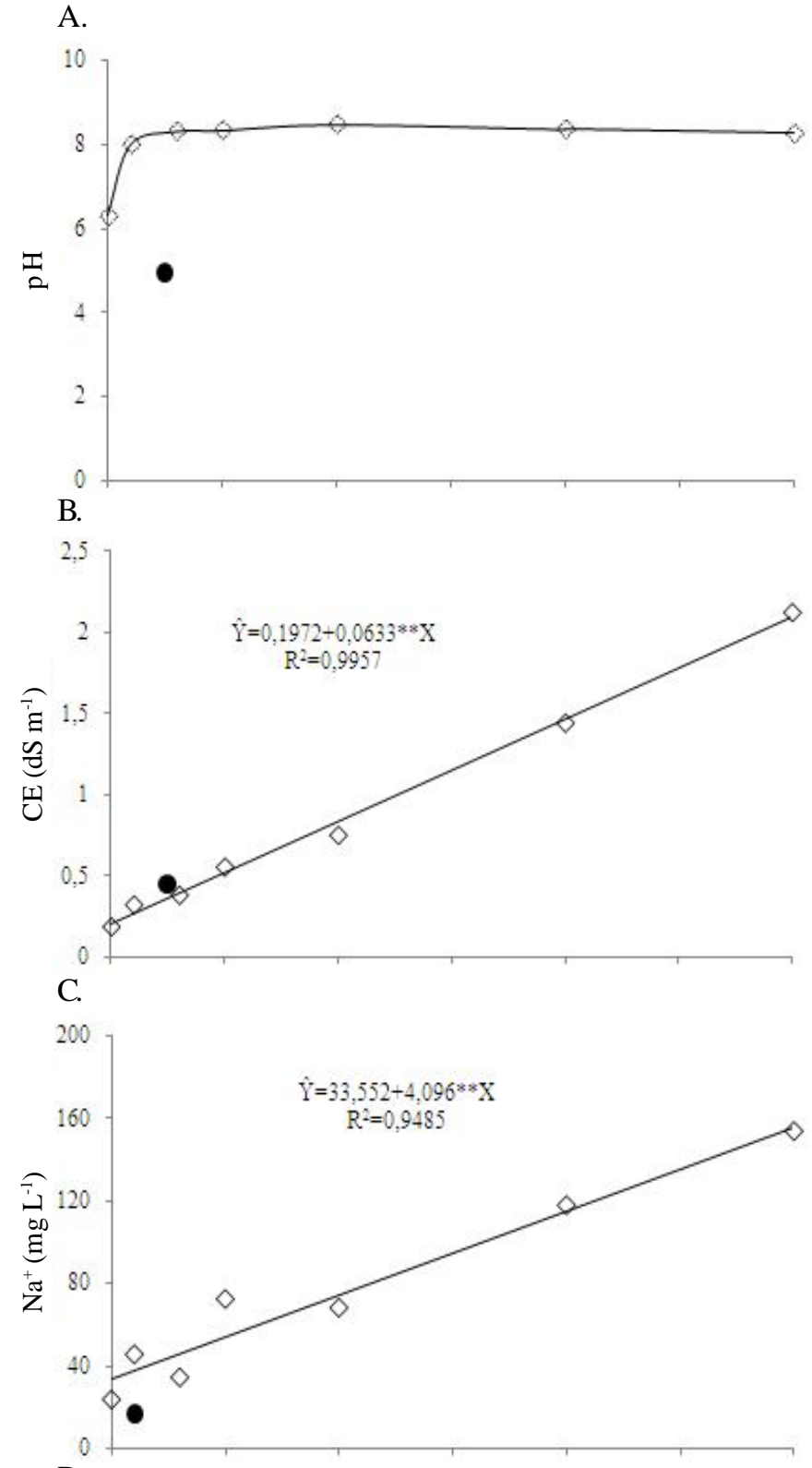

D.

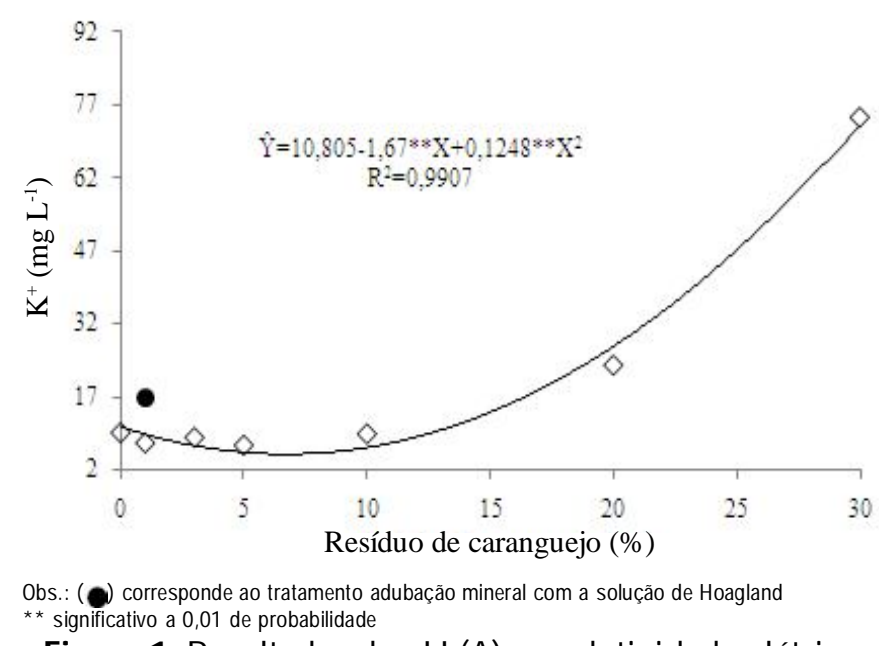

Figura 1. Resultados de $\mathrm{pH}(\mathrm{A})$, condutividade elétrica (B) e teores de $\mathrm{Na}^{+}(C)$ e $\mathrm{K}^{+}(\mathrm{D})$ do extrato 1:1 do solo, em função das diferentes percentagens de resíduo de caranguejo aplicado 

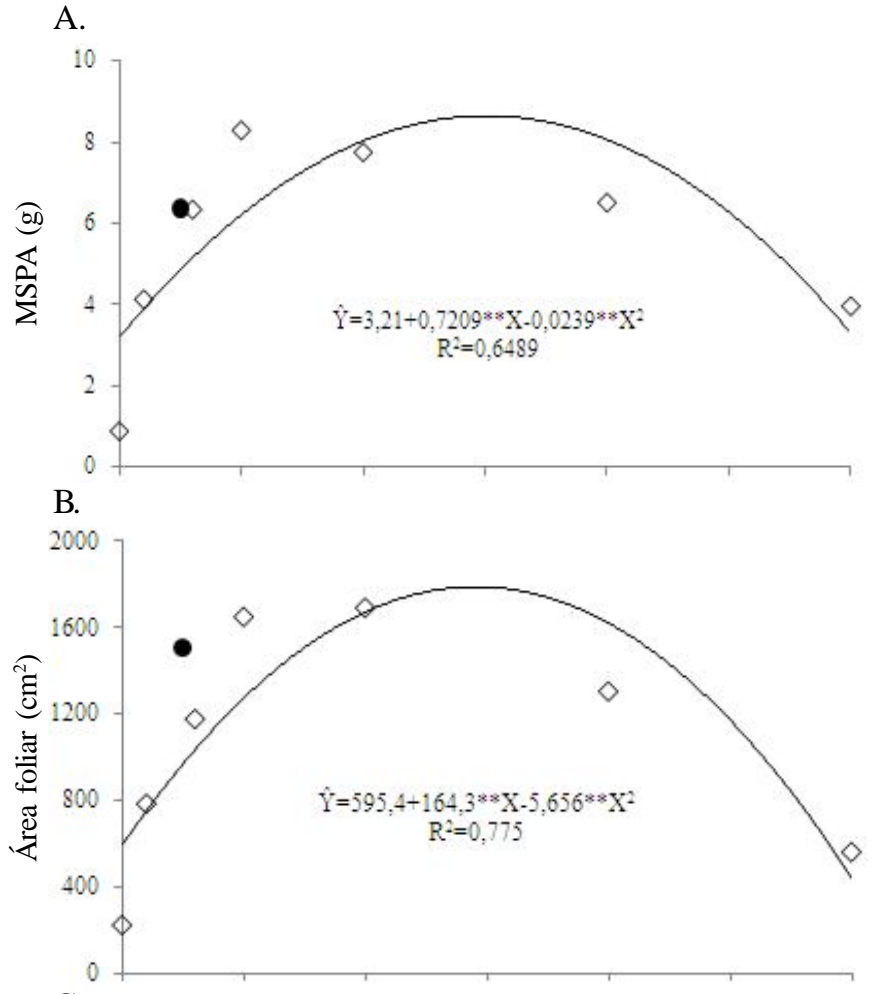

C.

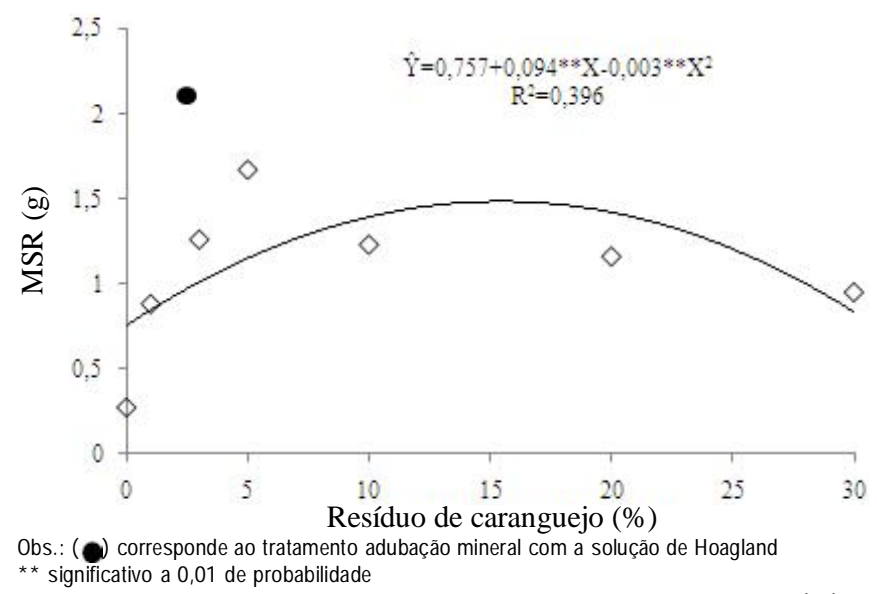

Figura 2. M assa seca da parte aérea total - M SPA (A), área foliar - AF (B) e massa seca da raiz - MSR (C) de plantas de melão, em função de diferentes percentagens de resíduo de caranguejo aplicado no solo

razão do aumento na salinidade e na concentração de $\mathrm{Na}^{+}$no substrato (Figura 1C). Comportamento similar foi observado por Araújo et al. (2009), que verificaram um incremento gradual no crescimento de feijão caupi com a aplicação de até $30 \%$ de resíduo de caranguejo.

A adubação com resíduos de caranguejo permitiu um incremento nos teores de clorofila, alcançando valores similares aos verificados no tratamento em que se aplicou a solução de Hoagland (Figura 3). O aumento na concentração de clorofila pode não só ser um indicativo de melhorias na nutrição mineral das plantas, mas também se correlacionar também com os teores foliares de nitrogênio.

Os teores foliares de carboidratos nas folhas do meloeiro mostraram tendência de aumento até a percentagem de 5\% da

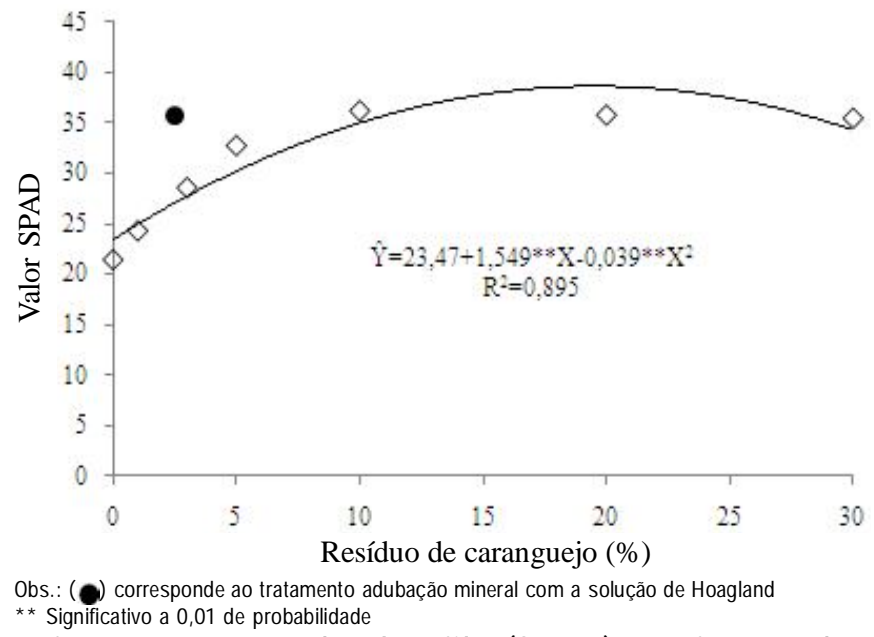

Figura 3. Teores de clorofila (SPAD) em função de diferentes percentagens de resíduo de caranguejo aplicado no solo

aplicação do resíduo de caranguejo, entretanto, a partir desse tratamento a produção de carboidrato foi comprometida (Figura 4A), em consequiência, talvez, do aumento da CE do solo, conforme observado na Figura1B. Por outro lado, verificou-se incremento nos teores de $\mathrm{N}$-aminossolúveis nos tratamentos com aplicação de até $10 \%$ de resíduo de caranguejo, com redução nos níveis superiores (Figura 4B).

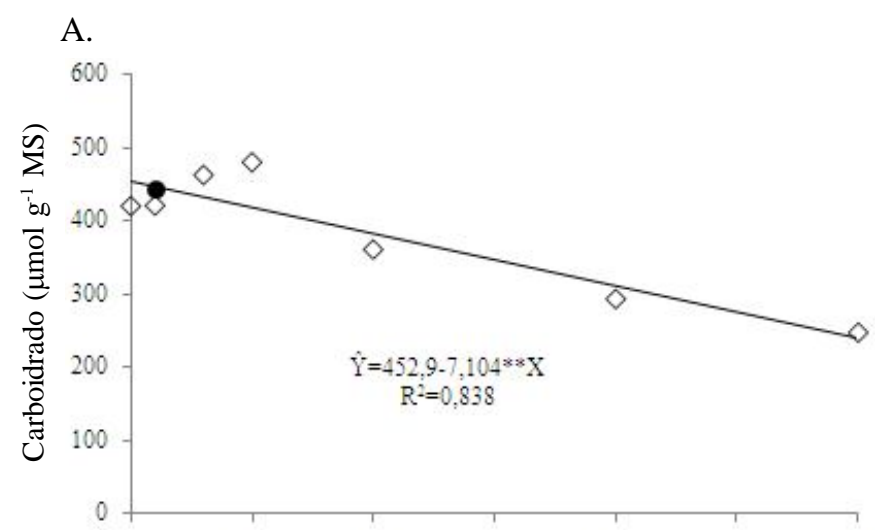

B.

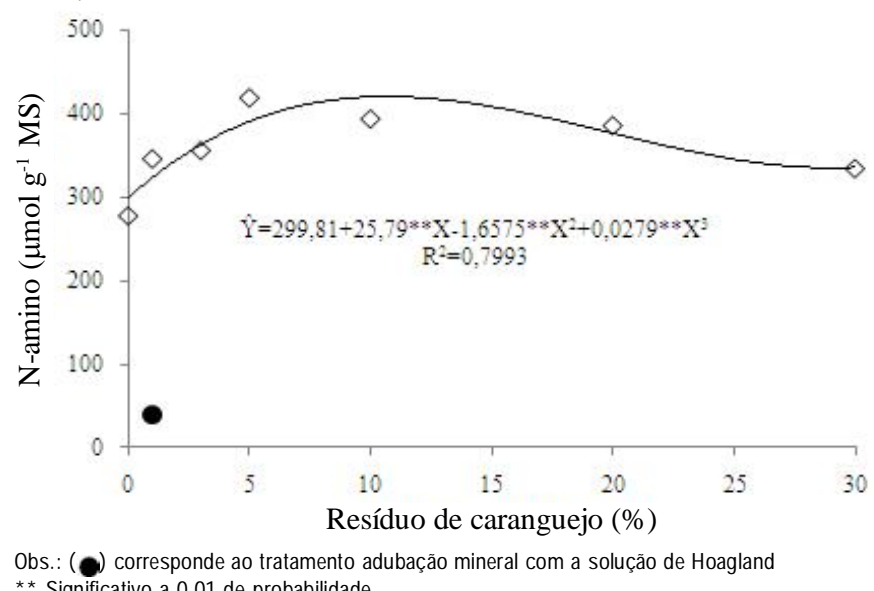

Figura 4. Teores de carboidratos (A) e de $\mathrm{N}$-aminossolúveis (B), em função de diferentes percentagens de resíduo de caranguejo aplicado no solo 
Considerando-se o tratamento com $5 \%$ de resíduo de caranguejo verifica-se que os teores de carboidratos solúveis e, principalmente, os de $\mathrm{N}$-aminossolúveis, foram iguais ou superiores aos verificados no tratamento que recebeu solução nutritiva. Segundo Benchimol et al. (2006), a adição da casca de caranguejo ao solo proporciona acréscimo na taxa fotossintética e na disponibilidade de $\mathrm{N}$ em plantas de pimenteira-do-reino, o que corrobora com um aumento de biomassa na parte aérea dessas plantas. Este aumento da taxa fotossintética com o uso de casca de caranguejo (Benchimol et al. 2006), pode ter contribuído para o aumento nos teores dos compostos orgânicos estudados no presente trabalho.

Os teores foliares de $\mathrm{Na}^{+}$foram maiores nas percentagens mais elevadas da aplicação do resíduo de caranguejo (Figura 5 A) refletindo, em parte, a composição do mesmo (Tabela 1) e os teores desse íon disponibilizados no solo, no final do experimento (Figura 1C). Os elevados teores de $\mathrm{Na}^{+}$nas folhas, notadamente nas maiores percentagens do resíduo de caranguejo, podem ter contribuído para a redução do crescimento das plantas de melão nesses tratamentos (Figura 5A), visto que em altas concentrações este íon se torna potencialmente tóxico, afetando o metabolismo e o desenvolvimento das plantas (Viégas et al., 2001).

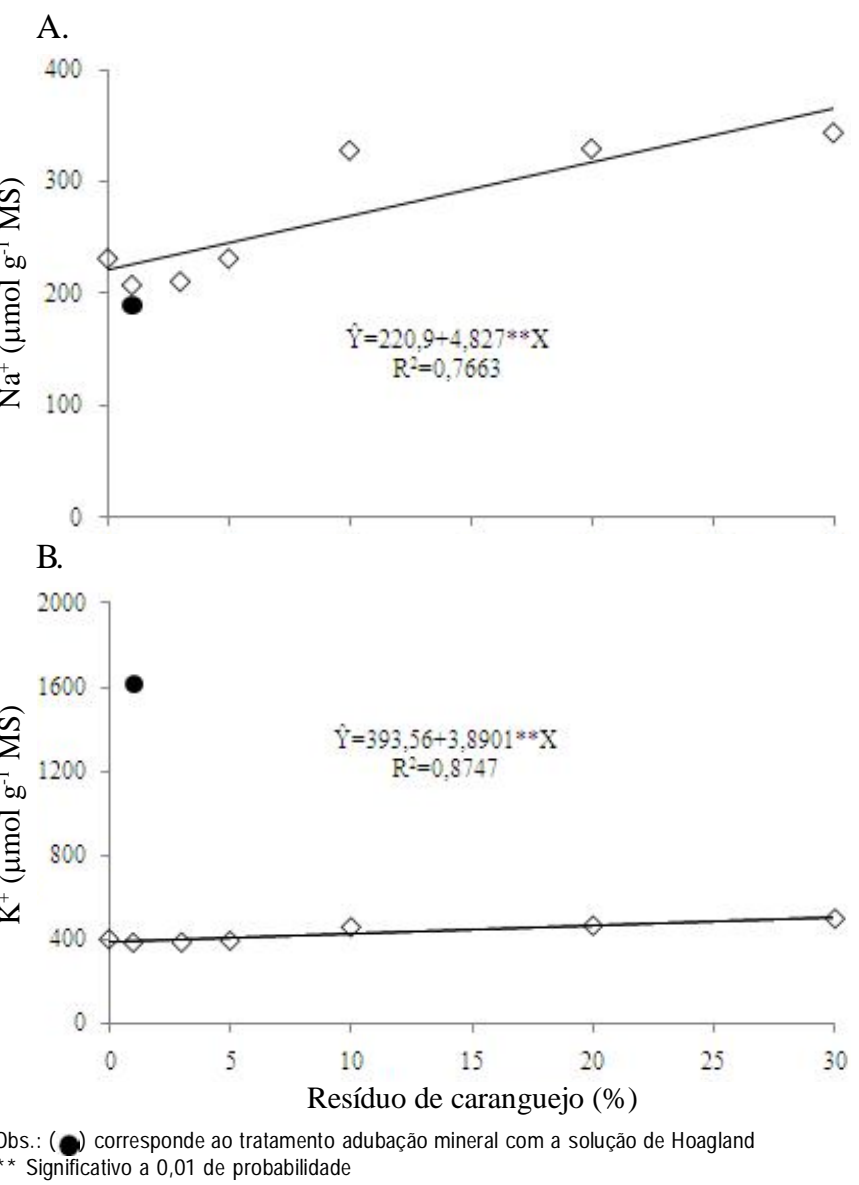

Figura 5. Teores de $\mathrm{Na}^{+}(\mathrm{A})$ e de $\mathrm{K}^{+}(\mathrm{B})$ em folhas de plantas de melão em função dos diferentes níveis de resíduo de caranguejo aplicado no solo
Os teores foliares de $\mathrm{K}^{+}$foram bem superiores nas plantas que receberam adubação mineral, mediante aplicação da solução de Hoagland, em relação aos tratamentos com resíduo de caranguejo (Figura 5B). Isto reflete a baixa disponibilidade do elemento no solo utilizado e indica que o resíduo de caranguejo não supre adequadamente as plantas com potássio. Além disso, a elevada concentração de cálcio no resíduo orgânico utilizado pode inibir competitivamente a absorção de $\mathrm{K}^{+}$(Marschner, 1995) contribuindo para a manutenção de teores bem inferiores aos das plantas que receberam a solução nutritiva.

\section{CONCLusões}

1. O incremento nas percentagens de resíduos de caranguejo aumenta significativamente os valores de $\mathrm{pH}, \mathrm{CE}, \mathrm{Na}^{+}$e $\mathrm{K}^{+}$no extrato $1: 1$ do solo.

2. A aplicação de $15,8 \%$ de resíduos de caranguejo propicia o crescimento máximo para as plantas de melão e nas percentagens subsequentes o crescimento é comprometido devido sobretudo ao aumento da salinidade do substrato.

3. O uso de resíduos de caranguejo como fonte de adubação orgânica até cerca de 5\% do volume do substrato incrementa os teores de carboidratos e $\mathrm{N}$-aminossolúveis.

\section{LITERATURA CITADA}

Araújo, F. J. F.; Aquino, M. D.; Aquino, B. F.; Bezerra, F. M. L.; Neto, F. C. Aplicação do composto orgânico produzido a partir de caranguejo uçá Ucides cordatus cordatus no cultivo de feijão caupi Vigna unguiculata (L.) Walp. Engenharia Ambiental: Pesquisa e Tecnologia, v.6, p.15-35, 2009.

Benchimol, R. L.; Sutton, J. C.; Dias Filho, M. B. Potencialidade da casca de caranguejo na redução da incidência de fusariose e na promoção do crescimento de mudas de Pimenteira-do-reino. Fitopatologia Brasileira, v.2, p.180-184, 2006.

Camargo, A. M. P.; Camargo Filho, W. P.; Camargo, F. P.; Alves, H. S. Produção em agropecuária orgânica: considerações sobre o quadro atual. Informações Econômicas, v.34, p.2124. 2004.

Cataldo, D. A.; Harron, M.; Schrader, L. E.; Youngs, V. L. Rapid colorimetric determination of nitrate in plant tissue by nitration of salicylic. Communications in Soil Science and Plant Analysis, v.6, p.71-80, 1975.

Dubois, M.; Gilles, K. A.; Hamilton, J. K.; Rebers, P. A.; Smith, F. Colorimetric method for determination of sugars and related substances. Analytical Chemistry, v.28, p.350-356, 1956.

Duenhas, L. H. Cultivo orgânico de melão: aplicação de esterco e de biofertilizantes e substâncias húmicas via fertirigação. Piracicaba: ESALQ/USP, 2004. 73p. Tese Doutorado 
Hoagland, D. R.; Arnon, D. T. The water-culture method for growing plants without soil. Berkeley: University of Berkely, 1950.32p. Circular 347

IBAMA - Instituto Brasileiro do Meio Ambiente e dos Recursos Naturais Renováveis - Caranguejo uçá. http://www.ibama.gov.br/ projetos_centros/centros/cepene/carang.htm. 20 Jan. 2006.

Marschner, H. Mineral nutrition of higher plants. 2.ed. London: Academy Press, 1995. 889p.

Menezes, J. B.; Gomes Júnior J.; Araújo, S. E.; Simões, A. N. Armazenamento de dois genótipos de melão amarelo sob condições ambiente. Horticultura Brasileira, v.19, p.42-49, 2001.
Rodrigues, P. N. F.; Rolim, M. M.; Bezerra Neto, E.; Pedrosa, E. M. R.; Oliveira, V. S. Crescimento e composição mineral do milho em função da compactação do solo e da aplicação de composto orgânico. Revista Brasileira de Engenharia Agrícola e Ambiental, v.13, p.94-99, 2008.

Viégas, R. A.; Silveira, J. A. G.; Lima Junior, A. R.; Queiroz, J. E.; Fausto, M. J. M. Effects of $\mathrm{NaCl}$ - Salinity on growth and inorganic solute accumulation in young cashew plants. Revista Brasileira de Engenharia Agrícola e Ambiental, v.5, p.216-22, 2001.

Yemm, E. W.; Cocking, E. C. The determination of amino-acids with ninhydrin. Analyst, v.80, p.209-213, 1955. 